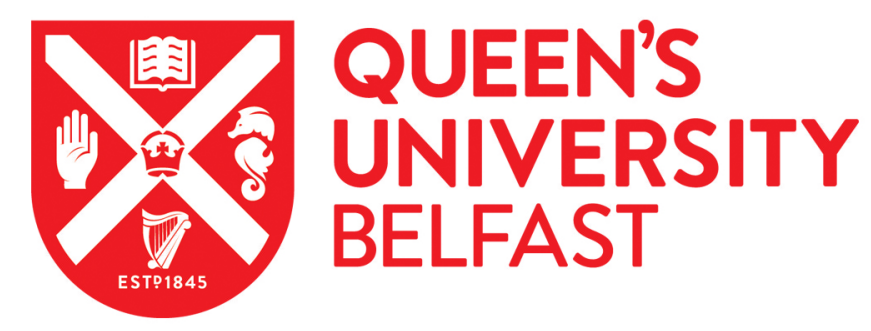

\title{
Video Feedback for Improving Parental Sensitivity and Attachment (Protocol)
}

O'Hara, L., Barlow, J., Livingstone, N., \& Macdonald, G. (2016). Video Feedback for Improving Parental Sensitivity and Attachment (Protocol). Cochrane database of systematic reviews (Online). https://doi.org/10.1002/14651858.CD012348

\section{Published in:}

Cochrane database of systematic reviews (Online)

\section{Document Version:}

Publisher's PDF, also known as Version of record

\section{Queen's University Belfast - Research Portal:}

Link to publication record in Queen's University Belfast Research Portal

\section{Publisher rights}

Copyright @ 2016 The Cochrane Collaboration. Published by John Wiley \& Sons, Ltd. This work is made available online in accordance with the publisher's policies. Please refer to any applicable terms of use of the publisher.

\section{General rights}

Copyright for the publications made accessible via the Queen's University Belfast Research Portal is retained by the author(s) and / or other copyright owners and it is a condition of accessing these publications that users recognise and abide by the legal requirements associated with these rights.

Take down policy

The Research Portal is Queen's institutional repository that provides access to Queen's research output. Every effort has been made to ensure that content in the Research Portal does not infringe any person's rights, or applicable UK laws. If you discover content in the Research Portal that you believe breaches copyright or violates any law, please contact openaccess@qub.ac.uk. 


\section{(E) Cochrane Library}

Cochrane Database of Systematic Reviews

\section{Video feedback for improving parental sensitivity and} attachment (Protocol)

O’Hara L, Barlow J, Livingstone N, Macdonald G

O'Hara L, Barlow J, Livingstone N, Macdonald G.

Video feedback for improving parental sensitivity and attachment.

Cochrane Database of Systematic Reviews 2016, Issue 9. Art. No.: CD012348.

DOI: 10.1002/14651858.CD012348.

www.cochranelibrary.com 
TABLE OF CONTENTS

HEADER . . . . . . . . . . . . . . . . . . . . . . . . . . . . . . . . . . . . . . . . 1

ABSTRACT . . . . . . . . . . . . . . . . . . . . . . . . . . . . . . . . . . . . . . . 1

BACKGROUND . . . . . . . . . . . . . . . . . . . . . . . . . . . . . . . . . . . .

OBJECTIVES . . . . . . . . . . . . . . . . . . . . . . . . . . . . . . . . . . . . . . . . . .

METHODS . . . . . . . . . . . . . . . . . . . . . . . . . . . . . . . . . . . . . . 44

ACKNOWLEDGEMENTS . . . . . . . . . . . . . . . . . . . . . . . . . . . . . . . . . . . . . . . . . .

REFERENCES . . . . . . . . . . . . . . . . . . . . . . . . . . . . . . . . . . . . . . . . . 9

APPENDICES . . . . . . . . . . . . . . . . . . . . . . . . . . . . . . . . . . . . . 14

CONTRIBUTIONS OF AUTHORS . . . . . . . . . . . . . . . . . . . . . . . . . . . . . . . . . . . . . . . .

DECLARATIONS OF INTEREST . . . . . . . . . . . . . . . . . . . . . . . . . . . . . . . . 17

SOURCES OF SUPPORT . . . . . . . . . . . . . . . . . . . . . . . . . . . . . . . . . . . . . . . . . . 


\title{
[Intervention Protocol]
}

\section{Video feedback for improving parental sensitivity and attachment}

\author{
Leeanne O’Hara ${ }^{1}$, Jane Barlow ${ }^{2}$, Nuala Livingstone ${ }^{3}$, Geraldine Macdonald ${ }^{4}$ \\ ${ }^{1}$ School of Social Sciences, Education and Social Work, Queen's University Belfast, Belfast, UK. ${ }^{2}$ Division of Mental Health and \\ Wellbeing, Warwick Medical School, University of Warwick, Coventry, UK. ${ }^{3}$ Cochrane Editorial Unit, Cochrane, London, UK. \\ ${ }^{4}$ School for Policy Studies, University of Bristol, Bristol, UK
}

Contact address: Leeanne O’Hara, School of Sociology, Social Policy and Social Work, Queen’s University Belfast, 6 College Park, Belfast, Northern Ireland, BT7 1LP, UK.1.ohara@qub.ac.uk.

Editorial group: Cochrane Developmental, Psychosocial and Learning Problems Group.

Publication status and date: New, published in Issue 9, 2016.

Citation: O’Hara L, Barlow J, Livingstone N, Macdonald G. Video feedback for improving parental sensitivity and attachment. Cochrane Database of Systematic Reviews 2016, Issue 9. Art. No.: CD012348. DOI: 10.1002/14651858.CD012348.

Copyright @ 2016 The Cochrane Collaboration. Published by John Wiley \& Sons, Ltd.

\begin{abstract}
A B S T R A C T
This is the protocol for a review and there is no abstract. The objectives are as follows:

To evaluate the effectiveness of video feedback for improving parental sensitivity and promoting attachment security.
\end{abstract}

\section{B A C K G R O U N D}

\section{Description of the condition}

\section{Attachment}

An infant's relationship with his or her mother is the first, and arguably the most important, relationship formed following birth. This emotional bond is known as a 'selective attachment' relationship. Attachment is a biobehavioural system that is a product of human evolution, and is designed to trigger protection in the face of perceived danger and its associated response, fear. When an infant is distressed, he or she is programmed to seek and secure proximity to, and contact with, the primary caregiver (Bowlby 1969). Attachment behaviour may be activated by circumstances internal to the child, such as illness, hunger or pain; by separation from the primary caregiver, such as when a mother leaves the room or discourages proximity; or by external events that cause distress, such as frightening events or rejection by others (Bowlby 1969). Depending on the intensity of the threat, the attachment behaviour may be terminated by the appearance of the caregiver or physical contact with them. The younger the child, or the more serious the threat, the more likely that only physical reassurance and containment will provide comfort. The attachment relationship is, therefore, dynamic in which the infant plays an active part (see Shin 2008).

Zeanah and colleagues describe the parent-child attachment relationship as a reciprocal relationship of seeker (infant) and provider (parent), the purpose of which is to provide the following (Zeanah 1993).

1. Comfort for distress.

2. Warmth, empathy and nurturance.

3. Emotional availability and regulation of emotions.

4. Physical and psychological protection.

Children translate their early relationship experiences into internal 
working models of themselves, other people and what they can expect from other people in response to their attachment needs. These working models are stable over time but can be revised in light of new information or experiences (see Goldberg 2000).

Infants whose caregivers provide sensitive and responsive care develop secure attachments to those carers. Children who experience insensitive, unpredictable or intrusive parenting develop attachments that are insecure, with adverse consequences for a range of aspects of their psychosocial development, including being more reliant on teachers, showing less positive affective expression and social problem-solving skills, more frustration and less persistence, more negative responses to others and less overall social competence (Sroufe 2005). In addition to children being classified as either secure or insecure, they may also be classified as either organised (i.e. secure) or disorganised (i.e. insecure); the latter refers to evidence of an approach and avoidance conflict in relation to the caregiver when the attachment system is activated (Main 1990a). Disorganised attachment occurs when children are frightened of the caregiver and have been exposed to a range of anomalous, atypical parent-infant interactions (Madigan 2006); and disorganisation is associated with predictors of later psychopathology, including externalising (Fearon 2010), and personality disorders (Steele 2010). Approximately $60 \%$ of children are securely attached, and the remainder (40\%) are insecure (Moullin 2014). For insecurely attached children, 25\% learn to avoid their parent when they are distressed (avoidant attachment) and 15\% learn to resist the parent, often because the parent responds unpredictably or amplifies their distress (disorganised or resistant attachment) (Moullin 2014). In addition, around $40 \%$ of disadvantaged children are classified as disorganised (Weinfield 2004), and as many as $80 \%$ of abused children receive this classification (Cyr 2010).

Although children usually have a particularly strong bond with one primary caregiver, most have more than one attachment relationship, often with fathers, siblings and grandparents (see, for example, Hallers-Haalboom 2014), and, as such, children can be securely attached to one parent but insecurely attached to another. The role of early relationship experiences and the development of infant self-regulatory skills have been linked to the child's ability to control behavioural and physiological responses such as, for example, anger (Gilliom 2002), aggression (Alink 2009), and anxiety (Hannesdottir 2007). It has also been found to be associated with increased executive functioning, which, in turn, is associated with proficiency and ability in core curriculum subjects such as English and Mathematics (Bernier 2010).

One key predictor of child attachment status is the parents' attachment status (Van Ijzendoorn 1995), but the impact of the parents' attachment status on the child's attachment appears to be mediated by parental sensitivity to infant cues; a systematic review of the antecedents of attachment security showed that maternal sensitivity was an important predictor, which explained around one third of the variance (De Wolff 1997).

\section{Caregiver sensitivity}

Ainsworth and colleagues defined sensitivity as a mother's ability to attend and respond to her infant in ways that accurately 'match' her infant's needs (Ainsworth 1978). Sensitive and responsive parents do each of the following (Ainsworth 1974).

1. Notice a child's signals.

2. Interpret these signals correctly.

3. Respond to signals in a timely and appropriate manner.

The concept of sensitivity, therefore, refers not to a set of maternal behaviours but to something much more dynamic and relational. Parental sensitivity can be compromised by a variety of factors. These include social influences such as social isolation (Belsky 2002; Kivijärvi 2004); psychological factors such as maternal depression (Dannemiller 1999; Karl 1995; Murray 1997), or personality disorder (Laulik 2013); maternal history of maltreatment (Pereria 2012), substance dependency (Eiden 2014), domestic violence (Levendosky 2006), or low self-esteem (Leerkes 2002; Shin 2008); or cognitive factors such as maternal preconceptions about parenting (Kiang 2004; Leerkes 2010). Child characteristics can also impact negatively on parental sensitivity, including infant prematurity (Singer 1999); the presence of excessive negative infant behaviour, for example, general distress (Leerkes 2002); and the child's proneness to anger (Ciciolla 2013), and irritability (Van den Boom 1991). Some studies have examined father involvement as a mediator of maternal sensitivity (see, for example, Stolk 2008), whilst others have examined the role of the father as caregiver (see, for example, Pelchat 2003). Comparative research on the relative sensitivity of mothers and fathers is scarce and therefore the findings are somewhat inconclusive; some studies report fathers as less sensitive than mothers (see Hallers-Haalboom 2014; Heerman 1994; Lovas 2005), while others have found no difference in parental sensitivity in terms of the gender of the caregiver (Pelchat 2003).

Although parental sensitivity has been found to be an important predictor of infant attachment security, it has also been found to explain around only one third of the variance (De Wolff 1997). Recent research has also highlighted the importance of mid-range contingency (Beebe 2010), and maternal reflective functioning (RF) (Slade 2005), or mind-mindedness (Meins 2001). Mid-range contingency refers to the ability of the parent to flexibly regulate both their own internal emotional states and the interaction with the baby, and is characterised by moments of synchrony or attunement, followed by rupture and then repair. Recent research found that interaction that occurred outside this mid-range, resulting from the parent's preoccupation either with self-regulation (e.g. depressed parents) or interactive regulation (e.g. anxious parents), was associated with insecure or disorganised attachment (Beebe 2010).

RF refers to the parent's capacity to understand their child's behaviour in terms of internal mental states (e.g. intentions, feelings, desires, etc.) (Slade 2005). High RF is associated with positive maternal parenting behaviours, such as flexibility and responsive- 
ness, and use of the mother as a secure base on the part of the infant, while low RF is associated with emotionally-unresponsive maternal behaviours such as withdrawal, hostility and intrusiveness (Kelly 2005; Slade 2005). 'Mind-mindedness' has similarly been found to be correlated with behavioural sensitivity and interactive synchrony (Meins 2001), and to be a better predictor of attachment security of the child at one year of age than maternal sensitivity (Lundy 2003; Meins 2001).

Other studies have identified a range of 'atypical' or 'anomalous' parent-infant interactions characterised as 'Fr-behaviours' (i.e. the behaviours of parents who are either frightened or frightening, or both (Jacobvitz 1997; Main 1990b), or who are hostile and helpless (Lyons-Ruth 2005)). 'Fr-behaviours' have been described as being subtle (e.g. periods of being dazed and unresponsive) or more overt (deliberately frightening children) (ibid), and such behaviours are strongly associated with a disorganised attachment (Madigan 2006).

\section{Description of the intervention}

Video feedback is a generic term that refers to the use of videotaped interactions of the parent and child to promote parental sensitivity; it is variously known as Video Interaction Guidance (VIG), Interaction Guidance (IG), Video Home Training (VHT) and Video Feedback Intervention to Promote Positive Parenting (VIPP). Developed by Harrie Biemans and colleagues in the 1980s, video feedback is a relationship-based parenting intervention that aims to enhance maternal sensitivity at the behavioural level (Kennedy 2010).

The core aspects of interventions based on video feedback are as follows.

1. Video-recording the parent-child interaction during play or aspects of daily caregiving.

2. Editing the recording to select micro-moments of interaction that demonstrate the child's contact initiatives and examples of the parent's attuned response to these signals.

3. Parent and 'guider' (the person responsible for the therapy) jointly reviewing the recordings, with the guider providing praise to the parent, not for the attunement per se, but for engaging in the evaluation of the interactions being viewed.

The intervention model is underpinned by two core concepts: intersubjectivity and mediated learning. Intersubjectivity, or 'shared moments of attunement', is modelled by the therapist (or 'guider') in their relationship and interactions with the parent, as well as being identified in the video recordings of the parent-child interaction. Mediated learning, or 'scaffolding', refers to the role played by adults in helping children learn how to do things that they might not otherwise manage alone. Mediated learning is also modelled by the guider in his or her relationships with the parent, as the guider helps the parent to describe what is happening in the clips being viewed, and what the parent and child in the video might be thinking or feeling, and to identify the consequences for the parent and the child (Kennedy 2011).

Video feedback may be delivered on both a one-to-one (e.g. VIPP, VIG) or group basis (e.g. Circle of Security (CS)), and has been used with first-time mothers (Velderman 2006); hardto-reach families (Kennedy 2010); parents of premature infants (Hoffenkamp 2015), or who have mental health problems, including postpartum depression (Vik 2006); middle-class, insensitive mothers (Kalinauskiene 2009); parents of autistic (Poslawsky 2015), maltreated (Moss 2011), and adopted children (Juffer 1997; Juffer 2005); parents of premature children and children with atopic dermatitis (Cassibba 2015); ethnic-minority parents (Yagmur 2014), and parents with an eating disorder (Stein 2006). Although video feedback is usually delivered in the home environment, it has also been used in clinical settings such as, for example, hospital environments with mothers of preterm babies (Hoffenkamp 2015), and residential treatment centres (Kennedy 2010). It is now used in over 15 countries by practitioners that work in a range of helping professions (e.g. social work, education, health) (Kennedy 2010).

\section{How the intervention might work}

Interventions designed to enhance parental sensitivity include three types of support (Berlin 2005), which are described as follows.

1. Interventions focused explicitly on enhancing sensitivity at the behavioural level.

2. Interventions to promote positive parental representations of their children.

3. Interventions that provide the parent with social support. These are not necessarily exclusive and some interventions involve all three types of activity. In a meta-analysis of interventions designed to promote maternal sensitivity and child attachment in early childhood, Bakermans-Kranenburg 2003 concluded that interventions were more effective when they included a component of video feedback with families.

In terms of the underpinning theoretical model, most forms of video feedback are attachment-based in the sense that they are aimed at enhancing maternal sensitivity, in order to promote secure attachment and reduce insecure/disorganised attachment. However, the presumed mechanisms by which this is achieved vary across various models of video feedback. All video feedback interventions primarily target the behavioural level using videorecorded episodes of the parent-child interaction. The attuned and mentalising stance of the guider provides an opportunity for the caregiver to experience attuned interactions with an adult who is able to think about the caregiver's internal states and the ways in which these might be informing their interactions with the baby. These attuned, mentalising interactions have the potential to improve a number of aspects of the caregiver's functioning, including their RF and their representations regarding their own attachment. 
In addition, the opportunity to view themselves in interaction with their baby and to observe positive responses from the infant, together with the guider using the video to prompt the parent to think about what the baby might be feeling, can bring about a range of meta-cognitive changes that result from the discrepancy between their own beliefs about their ability to parent and what they can see on the video, in addition to an increase in feelings of empowerment and self-efficacy, and their ability for RF (Kennedy 2011).

Some models of video feedback intervention include additional components that may provide a more explicit focus on representational issues. For example, Video Feedback Intervention to Promote Positive Parenting with Discussions on the Representational Level (VIPP-R) (Juffer 2008) involves the therapist addressing the mother's representations and attachment using discussions that may, for example, focus explicitly on the mother's own experiences of separation in early childhood, and those experienced with her own child (Klein Velderman 2006).

Other models involve the inclusion of teaching about sensitive discipline techniques: Video Feedback Intervention to Promote Positive Parenting - Sensitive Discipline (VIPP-SD). There is evidence that suggests the effectiveness of video feedback may vary with factors at both the level of the parent and of the child. For example, Bakermans-Kranenburg 1998 reported that amongst mothers with insecure attachments, those classed as 'insecure dismissing' (who idealise their own parents or minimise the importance of attachment relationships in their own lives) benefited most from video feedback, whilst those classed as 'insecure preoccupied' benefited most from video feedback with additional discussions about their childhood attachment experiences. Other studies have found evidence of differential susceptibility in the child, with highly reactive infants (Velderman 2006), and children with the dopamine receptor D4 (DRD4) 7-repeat allele (Bakermans-Kranenburg 2008), being more susceptible to change.

\section{Why it is important to do this review}

Improvment of the health and well-being of children is part of a global agenda. While the basic needs of children (e.g. food, sanitation, health care) are paramount to survival and development, living with an adult who is responsive to their needs is also important (Jones 2003). UNICEF 2008 highlights that a loving, stable and stimulating relationship with caregivers in the earliest months and years are critical for every aspect of a child's development. Research suggests that early targeted interventions aimed at increasing parental sensitivity and promoting attachment may be effective in promoting healthy child development (see, for example, Lieberman 1999; Schore 2001; Van Ijzendoorn 1995), and in preventing emotional maltreatment (Barlow 2010). Daly 2015 highlights the possible outcomes of providing family and parenting support based on various strategies implemented globally. The only quantitative review of the effectiveness of video feedback to date included both non-randomised between- and within-group designs (Fukkink 2008).

An early review by Fukkink 2008 concluded that video feedback was an effective means of improving parenting behaviour and attitudes, and child development. However, the paper does not provide the literature search dates for the review, which was submitted in June 2008; the review was very broad in its scope and includes all uses of video feedback with no age limits on the children (who ranged in age from birth to seven years, with an average age of 2.4 years (standard deviation $(\mathrm{SD})=2.7$ years). More importantly, the authors paid little attention to the quality of included studies (that is, there were no 'Risk of bias' assessments) and included quasi-experimental studies (no random assignment). A systematic review of current best evidence that addresses the methodological weakness of Fukkink 2008 will be of interest to policy makers and practitioners internationally, both in terms of evidence-based parenting interventions, and the promotion of infant and child mental health.

\section{O B JE C T IVES}

To evaluate the effectiveness of video feedback for improving parental sensitivity and promoting attachment security.

\section{METHODS}

\section{Criteria for considering studies for this review}

\section{Types of studies}

Randomised controlled trials (RCTs) and quasi-RCTs (in which the allocation to study arms is not truly random, for example, a form of alternation such as days of the week or by date of birth). We will exclude studies that have an alternative treatment but no control group.

\section{Types of participants}

Parent-infant dyads (including foster or adoptive carers), where the infant is aged between birth and four years 11 months, and where problems have been identified regarding the parent (e.g. bonding, depression, eating disorders, maltreatment) or the child (e.g. attachment or behaviour problems, challenging temperament, preterm birth).

If studies include a proportion of participants above four years 11 months, we will endeavour to obtain data on the sample aged up to four years 11 months. 
As this Cochrane review focuses on secondary prevention or 'at risk' parents/carers, we will exclude studies that use the intervention preventatively with a population group.

\section{Types of interventions}

Video feedback delivered in any setting compared with no treatment or treatment as usual. We will include studies in which the parent and child are filmed and then feedback is provided to the parent, either on a one-to-one basis or in groups, with the aim of improving the sensitivity of their interactions with the child or the mental representations of the parent.

We will include interventions that primarily involve the delivery of video feedback but that also provide one to two additional sessions related to the primary aim of the intervention (e.g. Video Feedback Intervention to Promote Positive Parenting (VIPP) with Discussions on the Representational Level (VIPP-R); VIPP - Sensitive Discipline (VIPP-SD)).

We will exclude interventions in which video feedback is used as part of a wider set of methods of working with the family and in which we cannot differentiate the effect of video feedback. We will also exclude programmes that use videotape modelling or videotape vignettes (e.g. Webster-Stratton 2013).

\section{Types of outcome measures}

\section{Primary outcomes}

1. Parental sensitivity (as measured by, for example, the Ainsworth Sensitivity Scale (ASS) (Ainsworth 1969), ChildAdult Relationship Experimental Index (CARE-Index) (Crittenden 2001), Parental Sensitivity Assessment Scale (PSAS) (Hoff 2004), Coding Interactive Behaviour (CIB) (Feldman 1998), Emotional Availability (EA) Scales (Biringen 2000), Global Ratings Scales of Mother-Infant Interaction (GRS) (Murray 1996), Maternal Behaviour Q-sort (MBQS) (Pederson 1999) or Nursing Child Assessment Teaching Scale (NCATS) (Sumner 1994)).

2. Parental reflective functioning (RF) (as measured by, for example, the Parent Development Interview (PDI) (unpublished manuscript by Aber 1985), PDI-Revised (PDI-R) (unpublished manuscript by Slade 2004)).

3. Attachment security (as measured by, for example, Attachment Q-set (AQS) (Waters 1987), or the Strange Situation Procedure (SSP) (Ainsworth 1978)).

4. Adverse effects: parent anxiety or stress (as measured by, for example, the Parenting Stress Index (PSI) (Abidin 1997) or the Parenting Stress Scale (PSS) (Berry 1995)).

\section{Secondary outcomes}

1. Infant mental health (as measured by behavioural assessments of emotional disorders, hyperactivity and conduct disorders).

2. Child physical and socioemotional development (as measured through, for example, the Bayley Scales of Infant and Toddler Development, third edition (Bayley-III) (Bayley 2005), Strengths and Difficulties Questionnaire (SDQ) (Goodman 1997)); child behaviour (as measured by, for example, the Child Behaviour Assessment Instrument (CBAI) (Samarakkody 2010)).

\section{Timing of outcome assessment}

We will collect outcome data at time points provided within the included studies and group these as postintervention (immediately upon completion), short term (up to six months), medium term (up to one year) and long term (over one year). However, we do not anticipate that we will identify many studies that report longterm outcomes.

\section{Search methods for identification of studies}

\section{Electronic searches}

We will search the electronic databases and trial registers listed below. We will not apply any date or language restrictions to the electronic searches and will secure translations where necessary.

1. The Cochrane Central Register of Controlled Trials (CENTRAL; current issue; part of the Cochrane Library), and which includes the Cochrane Developmental, Psychosocial and Learning Problems Group Specialised Register.

2. Ovid MEDLINE (1946 to current).

3. Embase (1974 to current; Ovid).

4. CINAHL Plus (1937 to current; EBSCOhost).

5. PsycINFO (1806 to current; Ovid).

6. Sociological Abstracts (1952 to current; ProQuest).

7. Social Sciences Citation Index (SSCI; 1970 to current; Web of Science).

8. Social Services Abstracts (1979 to current; ProQuest).

9. Conference Proceedings Citation Index - Social Science \& Humanities (CPCI-SS\&H; 1990 to current; Web of Science).

10. LILACS (1985 to current; lilacs.bvsalud.org/en).

11. Cochrane Database of Systematic Reviews (CDSR; current issue; part of the Cochrane Library).

12. Database of Abstracts of Reviews of Effects (DARE; current issue; part of the Cochrane Library).

13. Networked Digital Library of Theses and Dissertations (NDLTD; all available years; ndltd.org).

14. WorldCat (limited to dissertations and theses; all available years; Worldcat.org).

15. Clinicaltrials.gov (all available years; Clinicaltrials.gov). 
16. World Health Organization International Clinical Trials Registry Platform (WHO ICTRP; all available years; who.int/ ictrp/en).

We will search Ovid MEDLINE using the strategy in Appendix 1 . We will adapt it, as appropriate, for other databases.

\section{Searching other resources}

We will scrutinise bibliographies of included studies and relevant reviews to identify any additional relevant publications. We will draft a list of these studies to send to experts in the field and ask them to forward to us any published or unpublished work that we may have missed. We will also search other online sources, including the websites of relevant organisations and government departments (e.g. Association of Infant Mental Health (AIMH), UK (aimh.org.uk); United Nations International Children's Emergency Fund (UNICEF) Global Evaluation Database (unicef.org/evaldatabase); National Society for the Prevention of Cruelty to Children (NSPCC) Impact and Evidence Hub (nspcc.org.uk/services-and-resources/ impact-evidence-evaluation-child-protection); and the Association for Video Interaction Guidance UK (AVigUK) ( videointeractionguidance.net)). We will also use Google and Google Scholar to search the internet for unpublished work.

\section{Data collection and analysis}

\section{Selection of studies}

Two review authors ( $\mathrm{LOH}$ and JB) will independently screen titles and abstracts yielded by the searches against the inclusion criteria for the review. The review authors will then retrieve the full-text reports of all studies selected for potential inclusion, or those where there may be some uncertainty, and assess the texts for eligibility. Where the two review authors cannot make a final decision on the basis of the published information, we will write to the study authors to seek clarification. We will resolve any differences between the review authors ( $\mathrm{LOH}$ and JB) through discussion and, where necessary, we will consult the other review authors (GM, NL). We will record and document the excluded studies in the 'Characteristics of excluded studies' tables and will note the reason(s) for their exclusion. We will report the flow of studies using a PRISMA diagram (Liberati 2009).

\section{Data extraction and management}

Two review authors (LOH, NL) will independently extract data from each included study and will record the following information on a prepiloted data extraction form.

1. Participant characteristics (age, gender, ethnicity, location).
2. Intervention characteristics (including delivery, duration, outcomes and measures, and within-intervention variability).

3. Comparison characteristics (including whether the study used an active or inactive comparison).

4. Study characteristics (study design, sample size, length of follow-up, attrition or dropout, handling of missing data, methods of analysis).

5. Outcome data (relevant details on all primary and secondary outcome measures used, and summary data, including means, standard deviations (SDs), confidence intervals (CIs) and significance levels for continuous data and proportions for dichotomous data).

\section{Assessment of risk of bias in included studies}

Two review authors ( $\mathrm{LOH}$ and NL) will independently assess the risk of bias within each included study using the Cochrane 'Risk of bias' assessment tool (Higgins 2011a). We will classify judgements as either 'low risk of bias' 'high risk of bias' or 'unclear risk of bias' across the following seven domains for each included study (see Appendix 2) and record the judgements in a 'Risk of bias' table.

\section{Sequence generation}

Description: we will describe the method used to generate the allocation sequence in detail to assess whether it should have produced comparable groups.

Review authors' judgement: was the allocation concealment sequence adequately generated?

\section{Allocation concealment}

Description: we will describe the method used to conceal allocation sequence in sufficient detail to assess whether intervention schedules could have been foreseen in advance of, or during, recruitment.

Review authors' judgement: was allocation adequately concealed?

\section{Blinding of participants and personnel}

Description: we will describe any measures used to blind participants and personnel to assess their knowledge of which intervention a given participant might have received.

Review authors' judgement: was knowledge of the allocated intervention by participants and personnel adequately prevented during the study?

\section{Blinding of outcome assessors}

Description: we will describe any measures used to blind outcome assessors to assess their knowledge of which intervention a given participant might have received. 
Review authors' judgement: was knowledge of the allocated intervention by outcome assessors adequately prevented during the study?

\section{Incomplete outcome data}

Description: we will extract and report data on attrition and exclusions, as well the number of participants involved (compared with total randomised), reasons for attrition/exclusion (where reported or obtained from investigators) and any re-inclusions performed by the review authors if they retrieve missing data.

Review authors' judgement: were incomplete outcome data adequately addressed?

\section{Selective outcome reporting}

Description: we will attempt to assess the possibility of selective outcome reporting by investigators.

Review authors' judgement: are reports of the study free of suggestion of selective outcome reporting?

\section{Other sources of bias}

Description: we will describe any important concerns about bias not addressed in the other domains in the 'Risk of bias' tool.

Review authors' judgement: was the study was free of other problems that could put it at a high risk of bias (e.g. parent recruitment to the study)?

We will resolve any disagreements through discussion and, if necessary, will consult the second (JB) or fourth (GM) review author, or both.

\section{Measures of treatment effect}

We will calculate unadjusted treatment effects using Review Manager (RevMan) (RevMan 2014).

\section{Dichotomous outcome data}

We will calculate the odds ratios (OR) with a 95\% CI for dichotomous outcomes. For meta-analyses of dichotomous outcomes that we include in the 'Summary of findings' tables, we will express the results as absolute risks and will use high and low observed risks among the control groups as reference points.

\section{Continuous outcome data}

We will calculate mean difference (MD) values if all included studies use the same measurement scale, or standardised mean differences (SMDs) if studies use different measurements scales, and $95 \%$ CIs for continuous outcome measures. If necessary, we will compute effect estimates from $\mathrm{P}$ values, $t$ statistics, analysis of variance (ANOVA) tables or other statistics, as appropriate. We will calculate SMDs using Hedges $g$.

\section{Multiple outcomes}

When a study provides multiple, interchangeable measures of the same construct at the same point in time (e.g. multiple measures of maternal sensitivity), we will calculate the average SMD across these outcomes and the average of their estimated variances. This strategy aims to avoid the need to select a single measure and to avoid inflated precision in meta-analyses (i.e. preventing studies that report on more outcome measures receiving more weight in the analysis than comparable studies that report on a single outcome measure).

\section{Economics issues}

We will summarise available data on the costs of programmes within the included studies.

\section{Unit of analysis issues}

\section{Cluster-RCTs}

In the event that we identify relevant cluster-RCTs that meet the inclusion criteria of the review, we will deploy appropriate statistical methods based on the guidance provided in the Cochrane Handbook for Systematic Reviews of Interventions (Higgins 2011b). Where study authors have dealt appropriately with the clustered design in their analyses, we will try to obtain direct estimates of the effect (e.g. an OR with its CI). Where study authors have not dealt appropriately with the cluster design in their analyses, we will extract or calculate effect estimates and their standard errors (SEs) as for a parallel group trial, and adjust the SEs to account for the clustering (Donner 1980). To do this, we will need to identify an appropriate intraclass correlation coefficient (ICC), which describes the relative variability in outcome within and between clusters (Donner 1980). Where available, we will look for this information in the reports of relevant trials. If this is unavailable, we will try to obtain the information from the study authors. If this proves unsuccessful, we will use external estimates obtained from similar studies. We will find closest-matching scenarios (regarding both outcome measures and types of clusters) from existing databases of ICCs. If we are unable to identify any matches, we will perform sensitivity analyses using a high ICC of 0.1 , a moderate ICC of 0.01 and a small ICC or 0.001 , to cover a broader range of plausible values while still allowing for strong design effects for smaller studies (see Sensitivity analysis). Furthermore, we will combine these estimates and their corrected SEs from the clusterRCTs with those from parallel designs using the generic inverse variance method in RevMan (RevMan 2014). 


\section{Studies with multiple treatment groups}

In the primary analysis, we will combine results across all eligible intervention (Video Interaction Guidance (VIG)) groups and compare them with the combined results across all eligible control groups, and will make single pair-wise comparisons. Where studies compare more than one form of VIG with a control group(s) such that combining them prevents investigation of potential sources of heterogeneity, we will analyse each VIG group separately (against a common control group), but divide the sample size for common comparator groups proportionately across each comparison (Higgins 2011b, Section 16.5.5). This simple approach allows the use of standard software and prevents inappropriate double-counting of individuals.

\section{Dealing with missing data}

Where necessary, one review author $(\mathrm{LOH})$ will contact the authors of included studies to supply any unreported data, such as group means and SDs, details of dropouts and descriptive data regarding the intervention. If this fails or is not possible, we will follow the recommendations in the Cochrane Handbook for Systematic Reviews of Interventions (Higgins 2011b, Section 16.1) and we will do one of the following.

1. Only analyse the data available (if data is assumed to be missing at random).

2. Where appropriate, develop a strategy for data imputation (if we assume that data is not missing at random).

In the case of data imputation, we will specify the methods used in the 'Characteristics of included studies' tables. We will describe other missing data and dropouts/attrition for each included study in the 'Risk of bias' table, and we will discuss the extent to which these missing data could alter the results or conclusions of the review. We will assess the sensitivity of any primary meta-analyses to missing data using meta-regression to test for any effect of missingness on the summary estimates (Higgins 2011b, Section 16.1.2).

\section{Assessment of heterogeneity}

We will assess clinical heterogeneity across studies by examining the distribution of important participant factors (e.g. age, socioeconomic status, maternal maltreatment history, caregiver depression) and intervention characteristics (e.g. style, setting, personnel, context of delivery) among trials.

We will assess methodological heterogeneity across studies by comparing the distribution of study factors (e.g. allocation concealment, blinding of outcome assessment, losses to follow-up, treatment type, cointerventions).

We will describe statistical heterogeneity by computing the $\mathrm{I}^{2}$ statistic (Higgins 2002), which describes approximately the proportion of variation in point estimates that is due to heterogeneity rather than sampling error. In addition, we will use the $\mathrm{Chi}^{2}$ test
$(\mathrm{P}<0.10)$ of homogeneity to detect the strength of evidence that heterogeneity is genuine.

\section{Assessment of reporting biases}

We will draw funnel plots (estimated differences in treatment effects against their SE) if we identify 10 or more studies that provide data on an outcome. Asymmetry might be due to publication bias, but might also reflect a relationship between trial size and effect size such as when larger trials have lower compliance, and compliance is positively related to effect size. If we find such a relationship, we will examine the clinical variation of the studies (Sterne 2011, Section 10.4). As a direct test for publication bias, we will compare results extracted from published journal reports with results obtained from other sources.

\section{Data synthesis}

Where interventions are similar in (1) the age of the child(ren), (2) parent gender and (3) intensity, frequency and duration of VIG, we plan to synthesise results in a meta-analysis. We will use both fixed-effect and random-effects models and compare the results to assess the impact of statistical heterogeneity. When we report the results of the random-effects model, we will include an estimate of the between study variance $\left(\mathrm{Tau}^{2}\right)$. Unless the model is contraindicated (e.g. if there is funnel plot asymmetry), we plan to present the results from the random-effects model. In the occurrence of severe funnel plot asymmetry, we will present both fixed-effect and random-effects analyses, under the assumption that asymmetry suggests that neither model is appropriate. If both indicate a presence (or absence) of effect we will be reassured; if they do not agree we will report this. We will calculate all overall effects using inverse variance methods. If some primary studies report an outcome as a dichotomous measure and others use a continuous measure of the same construct, we will convert results for the former from an OR to a SMD, provided that we can assume the underlying continuous measure has approximately a normal or logistic distribution (otherwise we will perform two separate analyses).

\section{'Summary of findings' table}

We will create a 'Summary of findings' table per comparison. The comparisons will include the following.

1. Video feedback versus no intervention.

2. Video feedback versus alternative intervention.

We will follow the guidelines in the Cochrane Handbook for Systematic Reviews of Interventions (Schünemann 2011a, Section 11.5.3), and include the following six elements in these tables.

1. A list of all outcomes.

2. A measure of the typical burden of these outcomes.

3. Absolute and relative magnitude of effect.

4. Numbers of participants and studies that address these outcomes. 
5. A rating of the overall quality of evidence for each outcome.

6. Additional comments.

Two review authors (LOH, NL) will independently assess the quality of the evidence. They will use the following five Grading of Recommendations, Assessment, Development and Evaluation (GRADE) considerations to assess the quality of the evidence.

1. Limitations in study design and implementation: for RCTs, for example, these will include lack of allocation concealment, lack of blinding and large loss to follow-up.

2. Indirectness of evidence: for example, when findings are restricted to indirect comparisons between two interventions. RCTs that meet the eligibility criteria but which address a restricted version of the main review questions in terms of population, intervention, comparator or outcomes are another example of this and will also be downgraded.

3. Unexplained heterogeneity or inconsistency of results: we will look for robust explanations for heterogeneity in studies that yield widely differing estimates of effect.

4. Imprecision of results: we will downgrade the quality of evidence for those studies that include few participants and few events and thus have wide CIs.

5. Publication bias: we will downgrade the quality of evidence level if investigators fail to report studies or outcomes on the basis of results (Schünemann 2011b, Section 12.2.2).

We will use the GRADEprofiler Guideline Development Tool (GRADEpro GDT) to prepare the 'Summary of findings' tables, and specifically to enable us to produce relative effects and absolute risks associated with the interventions (GRADEpro GDT 2015). We will use all primary and secondary outcomes of interest to populate the 'Summary of findings' table.

\section{Subgroup analysis and investigation of heterogeneity}

We will investigate heterogeneity using subgroup analyses or metaregression, if appropriate. We will group the included studies and analyse them according to the intervention approach, including the following.

1. Intervention dose (e.g. intensity; duration).

2. Intervention type, including the use of additional components (e.g. VIG, VIPP-R, VIPP-SD).

3. Delivery method (i.e. group based versus individual delivery).

4. Participating carer (e.g. interventions that involve mothers and infants only; interventions that involve fathers and infants only; interventions that involve foster parents); and infant (e.g. prebirth or highly temperamental babies).

\section{Sensitivity analysis}

We will assess the robustness of findings to decisions made in obtaining them by conducting sensitivity analyses. We will perform sensitivity analyses by conducting the following reanalyses.

1. Reanalysis excluding studies at high risk of bias.

2. Reanalysis excluding studies with imputed data.

3. Reanalysis using different statistical approaches (Deeks 2011, Section 9.7).

\section{ACKNOW LEDGEMENTS}

This review is being produced within the Cochrane Developmental, Psychosocial and Learning Problems Group (CDPLPG). In particular we thank Margaret Anderson for her assistance with the search strategy.

\section{REF ER E N C E S}

\section{Additional references}

\section{Aber 1985}

Aber JL, Slade A, Berger B, Bresgi I, Kaplan M. The Parent Development Interview. Unpublished manuscript 1985.

\section{Abidin 1997}

Abidin RR. Parenting Stress Index: a measure of the parent-child system. In: Zalaquett CP, Wood RJ editor (s). Evaluating Stress: A Book of Resources. Lanham, MD: Scarecrow Press, 1997:277-91.

Ainsworth 1969

Ainsworth MDS. Maternal sensitivity scales. Power 1969;6: 1379-88.

\section{Ainsworth 1974}

Ainsworth MDS. Infant-mother attachment and social development. In: Richards MPM editor(s). The Integration of the Child into a Social World. London: Cambridge University Press, 1974:99-135.

\section{Ainsworth 1978}

Ainsworth MDS, Blehar MC, Waters E, Wall S. Patterns of Attachment: A Psychological Study of the Strange Situation. Hillsdale, NJ: Lawrence Erlbaum Associates, Inc, 1978.

\section{Alink 2009}

Alink LRA, Mesman J, Van Zeijl J, Stolk MN, Juffer J, Bakermans-Kranenburg MJ, et al. Maternal sensitivity moderates the relation between negative discipline and aggression in early childhood. Social Development 2009;18 (1):99-120. [DOI: 10.1111/j.1467-9507.2008.00478.x]

\section{Bakermans-Kranenburg 1998}

Bakermans-Kranenburg MJ, Juffer F, Van Ijzendoorn $\mathrm{MH}$. Interventions with video feedback and attachment discussions: does type of maternal insecurity make a 
difference?. Infant Mental Health Journal 1998;19(2): 200-19. [DOI: 10.1002/(SICI)1097-0355(199822)19:

2\%3C202::AID-IMHJ8\%3E3.0.CO;2-P]

Bakermans-Kranenburg 2003

Bakermans-Kranenburg MJ, Van Ijzendoorn MH, Juffer F. Less is more: meta-analyses of sensitivity and attachment interventions in early childhood. Psychological Bulletin 2003; 129(2):195-215. [DOI: 10.1037/0033-2909.129.2.195]

Bakermans-Kranenburg 2008

Bakermans-Kranenbrug MJ, Van IJzendoorn MH, Pijlman FT, Mesman J, Juffer F. Experimental evidence for differential susceptibility: dopamine D4 receptor polymorphism (DRD4 VNTR) moderates intervention effects on toddlers' externalising behavior in a randomised controlled trial. Developmental Psychology 2008;44(1): 293-300. [PUBMED: 18194028]

Barlow 2010

Barlow J, Schrader McMillan A. Safeguarding Children from Emotional Maltreatment: What Works. Safeguarding Children Across Services Series. London: Jessica Kingsley Publishers, 2010.

\section{Bayley 2005}

Bayley N. Bayley Scales of Infant and Toddler Development. 3rd Edition. United States: Pearson Clinical, 2005.

\section{Beebe 2010}

Beebe B, Jaffe J, Markese S, Buck K, Chen H, Cohen $\mathrm{P}$, et al. The origins of 12-month attachment: a microanalysis of 4-month mother-infant interaction. Attachment \& Human Development 2010;12(1-2):66-141. [PUBMED: 20390524]

\section{Belsky 2002}

Belsky J, Fearon RMP. Infant-mother attachment security, contextual risk, and early development: a moderational analysis. Development and Psychopathology 2002;14(2): 293-310. [PUBMED: 12030693]

\section{Berlin 2005}

Berlin LJ, Ziv Y, Amaya-Jackson L, Greenberg MT (editors). Enhancing Early Attachments: Theory, Research, Intervention and Policy. New York: The Guilford Press, 2005.

\section{Bernier 2010}

Bernier A, Carlson SM, Whipple N. From external regulation to self regulation: early parenting precursors of young children's executive functioning. Child Development 2010;81(1):326-39. [PUBMED: 20331670]

\section{Berry 1995}

Berry JO, Jones WH. The Parental Stress Scale: initial psychometric evidence. Journal of Social and Personal Relationships 1995;12(3):463-72. [DOI: 10.1177/ 0265407595123009]

\section{Biringen 2000}

Biringen Z. Emotional availability: conceptualization and research findings. American Journal of Orthopsychiatry 2000; 70(1):104-14. [DOI: 10.1037/h0087711]

\section{Bowlby 1969}

Bowlby J. Attachment and Loss, Volume 1: Attachment. New York: Basic Books, 1969.

\section{Cassibba 2015}

Cassibba R, Castoro G, Costantino E, Sette G, Van Ijzendoorn $\mathrm{MH}$. Enhancing maternal sensitivity and infant attachment security with video feedback: an exploratory study in Italy. Infant Mental Health Journal 2015;36(1): 53-61. [DOI: 10.1002/imhj.21486]

\section{Cates 2016 [pers comm]}

Cates C (UK Cochrane Centre, Oxford), O’Mathuna D (Cochrane Ireland, Dublin). RA3 \& RA4 workshops delivered to Cochrane HRB/R\&D Fellows [personal communication]. Unpublished handout 27-28 April 2016; Vol. Located at Dublin.

\section{Ciciolla 2013}

Ciciolla L, Crnic KA, West SG. Determinants of change in maternal sensitivity: contributions of context, temperament, and developmental risk. Parenting: Science and Practice 2013;13(3):178-95. [DOI: 10.1080/ 15295192.2013.756354]

\section{Crittenden 2001}

Crittenden PM. CARE-INDEX Infants and Toddlers Coding Manual. Miami: Family Relations Institute, 2001.

Cyr 2010

Cyr C, Euser EM, Bakermans-Kranenburg MJ, Van Ijzendoorn MH. Attachment security and disorganization in maltreating and high-risk families: a series of metaanalyses. Development and Psychopathology 2010;22(1): 87-108. [DOI: 10.1017/S0954579409990289]

Daly 2015

Daly MR, Bray Z, Bruckauf J, Byrne A, Margaria N, Pecnik N, et al. Family and Parenting Support: Policy and Provision in a Global Context, Innocenti Insight. Florence: UNICEF Office of Research-Innocenti, 2015.

\section{Dannemiller 1999}

Dannemiller JL. Chronicity of maternal depressive symptoms, maternal sensitivity and child functioning at 36 months. NICHD Early Child Care Research Network. Developmental Psychology 1999;35(5):1297-310. [PUBMED: 10493655]

\section{De Wolff 1997}

De Wolff MS, Van Ijzendoorn MH. Sensitivity and attachment: a meta-analysis on parental antecedents of infant attachment. Child Development 1997;68(4):571-91. [PUBMED: 9306636]

\section{Deeks 2011}

Deeks JJ, Higgins JPT, Altman DG on behalf of the Cochrane Statistical Methods Group. Chapter 9: Analysing data and undertaking meta-analyses. In: Higgins JPT, Green S (editors). Cochrane Handbook for Systematic Reviews of Interventions Version 5.1.0 [updated March 2011]. The Cochrane Collaboration, 2011. Available from www.cochrane-handbook.org.

\section{Donner 1980}

Donner A, Koval JJ. The estimation of intraclass correlation in the analysis of family data. Biometrics 1980;36(1):19-25. [DOI: $10.2307 / 2530491]$ 


\section{Eiden 2014}

Eiden RD, Godleski S, Colder CR, Schuetze P. Prenatal cocaine exposure: the role of cumulative environmental risk and maternal harshness in the development of child internalizing behavior problems in kindergarten. Neurotoxicology and Teratology 2014;44:1-10. [DOI: 10.1016/j.ntt.2014.04.002]

Fearon 2010

Fearon RP, Bakermans-Kranenburg MJ, Van Ijzendoorn MH, Lapsley AM, Roisman GI. The significance of insecure attachment and disorganization in the development of children's externalizing behavior: a meta-analytic study. Child Development 2010;81(2):435-56. [DOI: 10.1111/ j.1467-8624.2009.01405.x]

Feldman 1998

Feldman R. Coding Interactive Behaviour Manual. Ramat Gan, Israel: Bar-Ilan University, 1998.

\section{Fukkink 2008}

Fukkink RG. Video feedback in widescreen: a meta-analysis of family programs. Clinical Psychology Review 2008;28(6): 904-16. [DOI: 10.1016/j.cpr.2008.01.003]

\section{Gilliom 2002}

Gilliom M, Shaw DS, Beck JE, Schonberg MA, Lukon JL. Anger regulation in disadvantaged preschool boys: strategies, antecedents, and the development of self-control. Developmental Psychology 2002;38(2):222-35. [PUBMED: 11881758]

\section{Goldberg 2000}

Goldberg S. Attachment and Development. London: Arnold, 2000.

\section{Goodman 1997}

Goodman R. The Strengths and Difficulties Questionnaire: a research note. Journal of Child Psychology and Psychiatry 1997;38(5):581-6. [DOI: 10.1111/ j.1469-7610.1997.tb01545.x]

GRADEpro GDT 2015 [Computer program] McMaster University. GRADEpro GDT: GRADEpro Guideline Development Tool. McMaster University, 2015 (developed by Evidence Prime, Inc.). Available from www.gradepro.org.

\section{Hallers-Haalboom 2014}

Hallers-Haalboom ET, Mesman J, Groeneveld MG, Endendijk JJ, Van Berkel SR, Van der Pol LD, et al. Mothers, fathers, sons and daughters: parental sensitivity in families with two children. Journal of Family Psychology 2014;28(2):138-47. [DOI: 10.1037/a0036004]

Hannesdottir 2007

Hannesdottir DK, Ollendick TH. The role of emotion regulation in the treatment of child anxiety disorders. Clinical Child and Family Psychology Review 2007;10(3): 275-93. [PUBMED: 17705098]

Heerman 1994

Heerman JA, Jones LC, Wikoff RL. Measurement of parent behaviour during interactions with their infants. Infant
Behaviour and Development 1994;17(3):311-21. [DOI: 10.1016/0163-6383(94)90011-6]

\section{Higgins 2002}

Higgins JPT, Thompson SG. Quantifying heterogeneity in meta-analysis. Statistics in Medicine 2002;21(11):1539-58. [PUBMED: 12111919]

\section{Higgins 2011a}

Higgins JPT, Altman DG, Sterne JAC on behalf of the Cochrane Statistical Methods Group and the Cochrane Bias Methods Group. Chapter 8: Assessing risk of bias in included studies. In: Higgins JPT, Green S (editors). Cochrane Handbook for Systematic Reviews of Interventions Version 5.1.0 [updated March 2011]. The Cochrane Collaboration, 2011. Available from www.handbook.cochrane.org.

\section{Higgins 2011b}

Higgins JPT, Deeks JJ, Altman DG on behalf of the Cochrane Statistical Methods Group. Chapter 16: Special topics in statistics. In: Higgins JPT, Green S (editors). Cochrane Handbook for Systematic Reviews of Interventions Version 5.1.0 [updated March 2011]. The Cochrane Collaboration, 2011. Available from www.cochrane-handbook.org.

\section{Hoff 2004}

Hoff B, Munck H, Greisen G. Assessment of parental sensitivity towards pre-school children born with very low birth weight. Scandinavian Journal of Psychology 2004;45 (1):85-9. [DOI: 10.1111/j.1467-9450.2004.00382.x]

\section{Hoffenkamp 2015}

Hoffenkamp HN, Tooten A, Hall RAS, Braeken J, Eliëns MP, Vingerhoets ADJJM, et al. Effectiveness of hospitalbased video interaction guidance on parental interactive behaviour, bonding, and stress after preterm birth: a randomised control trial. Journal of Consulting and Clinical Psychology 2015;83(2):416-29. [DOI: 10.1037/a0038401]

\section{Jacobvitz 1997}

Jacobvitz D, Hazen NL, Riggs S. Disorganised mental processes in mothers, frightened/frightening behaviour in caregivers and disorientated, disorganised behaviour in infancy. Biennial meeting of the Society for Research in Child Development; 1997 April 3-6; Washington (DC). Washington DC, 1997.

\section{Jones 2003}

Jones G, Steketee RW, Black RE, Bhutta ZA, Morris SS, The Bellagio Child Survival Study Group. How many child deaths can we prevent this year?. Lancet 2003;362(9377): 65-71. [DOI: 10.1016/S0140-6736(03)13811-1]

\section{Juffer 1997}

Juffer F, Hoksbergen RA, Riksen-Walraven JM, Kohnstamm GA. Early intervention in adoptive families: supporting maternal sensitive responsiveness, infant-mother attachment, and infant competence. Journal of Child Psychology and Psychiatry 1997;38(8):1039-50. [DOI: 10.1111/j.1469-7610.1997.tb01620.x] 
Juffer 2005

Juffer F, Bakermans-Kranenburg MJ, Van Ijzendoorn $\mathrm{MH}$. The importance of parenting in the development of disorganised attachment: evidence from a preventative intervention study in adoptive families. Journal of Child Psychology and Psychiatry 2005;46(3):263-74. [DOI: 10.1111/j.1469-7610.2004.00353.x]

\section{Juffer 2008}

Juffer F, Bakermans-Kranenburg MJ, van Ijzendoorn MH. Promoting Positive Parenting: An Attachment Based Intervention. Mahwah, NJ: Erlbaum, 2008.

\section{Kalinauskiene 2009}

Kalinauskiene L, Cekuoliene C, Van Ijzendoorn MH, Bakermans-Kranenburg MJ, Juffer F, Kusakovskaja I. Supporting insensitive mothers: the Vilinus randomised trial of video-feedback intervention to promote maternal sensitivity and infant attachment security. Child: Care, Health and Development 2009;35(5):613-23. [DOI: 10.1111/j.1365-2214.2009.00962.x]

\section{Karl 1995}

Karl D. Maternal responsiveness of socially high-risk mothers to the elicitation cues of their 7-month-old infants. Journal of Pediatric Nursing 1995;10(4):254-63. [DOI: 10.1016/S0882-5963(05)80022-3]

Kelly 2005

Kelly K, Slade A, Grienenberger JF. Maternal reflective functioning, mother-infant affective communication, and infant attachment: exploring the link between mental states and observed caregiving behavior in the intergenerational transmission of attachment. Attachment \& Human Development 2005;7(3):299-311. [DOI: 10.1080/ 14616730500245963 ]

\section{Kennedy 2010}

Kennedy H, Landor M, Todd L. Video Interaction Guidance as a method to promote secure attachment. Educational and Child Psychology 2010;27(3):59-72.

\section{Kennedy 2011}

Kennedy H, Landor M, Todd L (editors). Video Interaction Guidance: A Relationship-Based Intervention to Promote Attunement, Empathy and Wellbeing. London: Jessica Kingsley Publishers, 2011.

\section{Kiang 2004}

Kiang L, Moreno AJ, Robinson JL. Maternal preconceptions about parenting predict child temperament, maternal sensitivity, and children's empathy. Developmental Psychology 2004;40(6):1081-92.

\section{Kivijärvi 2004}

Kivijärvi M, Räihä H, Virtanen S, Lertola K, Piha J. Maternal sensitivity behavior and infant crying, fussing and contented behaviour: the effects of mother's experienced social support. Scandinavian Journal of Psychology 2004;45 (3):239-46. [DOI: 10.1111/j.1467-9450.2004.00400.x]

\section{Klein Velderman 2006}

Klein Velderman M, Bakermans-Kranenburg MJ, Juffer F, Van IJzendoorm MH, Manglesdorf SC, Zevalkink J.
Preventing preschool externalizing behavior problems through video-feedback intervention in infancy. Infant Mental Health 2006;27(5):466-93. [DOI: 10.1002/ imhj.20104]

\section{Laulik 2013}

Laulik S, Chou S, Browne KD, Allam J. The link between personality disorder and parenting behaviours: a systematic review. Aggression and Violent Behaviour 2013;18(6): 644-55. [DOI: 10.1016/j.avb.2013.07.017]

\section{Leerkes 2002}

Leerkes EM, Crockenberg SC. The development of maternal self-efficacy and its impact on maternal behavior. Infancy 2002;3(2):227-47. [DOI: 10.1207/S15327078IN0302_7]

\section{Leerkes 2010}

Leerkes EM. Predictors of maternal sensitivity to infant distress. Parenting, Science and Practice 2010;10(3):219-39. [PUBMED: 20824194]

\section{Levendosky 2006}

Levendosky AA, Leahy KL, Bogat GA, Davidson WS, Von Eye A. Domestic violence, maternal parenting, maternal mental health, and infant externalizing behavior. Journal of Family Psychology 2006;20(4):544-52. [DOI: 10.1037/ 0893-3200.20.4.544]

\section{Liberati 2009}

Liberati A, Altman D, Tetzlaff J, Mulrow C, Gøtzsche PC, Ioannidis JPA, et al. The PRISMA statement for reporting systematic reviews and meta-analyses of studies that evaluate healthcare interventions: explanation and elaboration. BMJ 2009;339:b2700. [DOI: 10.1136/bmj.b2700]

\section{Lieberman 1999}

Lieberman AF, Zeanah CH, Cassidy J. Contributions of attachment theory to infant-parent psychotherapy and other interventions with infants and young children. In: Cassidy J, Shaver PR editor(s). Handbook of Attachment: Theory, Research and Clinical Applications. New York: Guilford Press, 1999:555-74.

\section{Lovas 2005}

Lovas GS. Gender and patterns of emotional availability in mother-toddler and father-toddler dyads. Infant Mental Health Journal 2005;26(4):327-53. [DOI: 10.1002/ imhj.20056]

\section{Lundy 2003}

Lundy BL. Father- and mother-infant face-to-face interactions: differences in mind-related comments and infant attachment?. Infant Behavior and Development 2003; 26(2):200-12. [DOI: 10.1016/S0163-6383(03)00017-1]

\section{Lyons-Ruth 2005}

Lyons-Ruth K, Yellin C, Melnick S, Atwood G. Expanding the concept on unresolved mental states: hostile/helpless states of mind on the Adult Attachment Interview are associated with the disrupted mother-infant communication and infant disorganization. Developmental Psychopathology 2005; 17(1):1-23.

\section{Madigan 2006}

Madigan S, Bakermans-Kranenburg MJ, Van Ijzendoorn MH, Moran G, Pederson DR, Benoit D. Unresolved states 
of mind, anomalous parenting behavior, and disorganized attachment: a review and meta-analysis of a transmission gap. Attachment \& Human Development 2006;8(2):89-111. [DOI: $10.1080 / 14616730600774458$ ]

\section{Main 1990a}

Main M. Cross-cultural studies of attachment organization: recent studies, changing methodologies, and the concept of conditional strategies. Human Development 1990;33(1): 48-61. [DOI: 10.1159/000276502]

\section{Main 1990b}

Main M, Hesse E. Parents' unresolved traumatic experiences are related to infant disorganised attachment status: is frightened and/or frightening behaviour the linking mechanism?. In: Greenberg MT, Cicchetti D, Cummings EM editor(s). Attachment in the Pre-school Years: Theory, Research and Intervention. Chicago: University of Chicago Press, 1990:161-82.

\section{Meins 2001}

Meins E, Fernyhough C, Fradley E, Tuckey M. Rethinking maternal sensitivity: mothers' comments on infants' mental processes predict security of attachment at 12 months. Journal of Child Psychology and Psychiatry 2001;42(5): $637-48$.

\section{Moss 2011}

Moss E, Dubois-Comtois K, Cyr C, Tarabulsy GM, St-Laurent D, Bernier A. Efficacy of a home visitingintervention aimed at improving maternal sensitivity, child attachment and behavioural outcomes for maltreated children: a randomised control trial. Development and Psychopathology 2011;23(1):195-210. [DOI: 10.1017/ S0954579410000738]

\section{Moullin 2014}

Moullin S, Waldfogel J, Washbrook E. Baby bonds: parenting, attachment and a secure base for children. www.suttontrust.com/researcharchive/baby-bonds/ (accessed 3 December 2015).

\section{Murray 1996}

Murray L, Fiori-Cowley A, Hooper R, Cooper P. The impact of postnatal depression and associated adversity on early mother-infant interactions and later infant outcome. Child Development 1996;67(5):2512-26. [DOI: 10.2307/ 1131637]

\section{Murray 1997}

Murray L, Cooper PJ. Effects of postnatal depression on infant development. Archives of Disease in Childhood 1997; 77(2):99-101. [DOI: 10.1136/adc.77.2.99]

\section{Pederson 1999}

Pederson DR, Moran G. The relationship imperative: arguments for a broad definition of attachment. Journal of Family Psychology 1999;13(4):496-500.

\section{Pelchat 2003}

Pelchat D, Bisson J, Bois C, Saucier J-F. The effects of early relational antecedents and other factors on the parental sensitivity of mothers and fathers. Infant and Child Development 2003;12(1):27-51. [DOI: 10.1002/icd.335]

\section{Pereria 2012}

Pereria J, Vickers K, Atkinson L, Gonzalez A, Wekerle C, Levitan R. Parenting stress mediates between maternal maltreatment history and maternal sensitivity in a community sample. Child Abuse \& Neglect 2012;36(5): 433-7. [DOI: 10.1016/j.chiabu.2012.01.006]

Poslawsky 2015

Poslawsky IE, Naber FB, Bakermans-Kranenburg MJ, van Daalen E, van Engeland H, van IJzendoorn MH. Video-feedback Intervention to promote Positive Parenting adapted to Autism (VIPP-AUTI): a randomised controlled trial. Autism 2015;19(5):588-603. [PUBMED: 24919961]

\section{RevMan 2014 [Computer program]}

The Nordic Cochrane Centre, The Cochrane Collaboration. Review Manager (RevMan). Version 5.3. Copenhagen: The Nordic Cochrane Centre, The Cochrane Collaboration, 2014.

\section{Samarakkody 2010}

Samarakkody DC, Fernando DN, Perera H, McClure RJ, De Silva H. The Child Behaviour Assessment Instrument: development and validation of a measure to screen for externalising child behaviour problems in community setting. International Journal of Mental Health Systems 2010; 4:13. [DOI: $10.1186 / 1752-4458-4-13$ ]

\section{Schore 2001}

Schore AN. Effects of a secure attachment relationship on right brain development, affect regulation and infant mental health. Infant Mental Health Journal 2001;22(1-2): 7-66. [DOI: 10.1002/1097-0355(200101/04)22:1\%3C7:: AID-IMHJ2\%3E3.0.CO;2-N]

\section{Schünemann 2011a}

Schünemann HJ, Oxman AD, Higgins JPT, Gunn EV, Glasziou P, Guyatt GH on behalf of the Cochrane Applicability and Recommendations Methods Group and the Cochrane Statistical Methods Group. Chapter 11: Presenting results and 'Summary of findings' tables. In: Higgins JPT, Green S (editors). Cochrane Handbook for Systematic Reviews of Interventions Version 5.1.0 [updated March 2011]. The Cochrane Collaboration, 2011. Available from www.cochrane-handbook.org.

\section{Schünemann 2011b}

Schünemann HJ, Oxman AD, Gunn EV, Higgins JPT, Deeks JJ, Glasziou P, et al. Chapter 12: Interpreting results and drawing conclusions. In: Higgins JPT, Green $S$ (editors). Cochrane Handbook for Systematic Reviews of Interventions Version 5.1.0 [updated March 2011]. The Cochrane Collaboration, 2011. Available from www.cochrane-handbook.org.

Shin 2008

Shin H, Park YJ, Ryu H, Seomun GA. Maternal sensitivity: a concept analysis. Journal of Advanced Nursing 2008;64(3): 304-14. [PUBMED: 18764848]

\section{Singer 1999}

Singer LT, Salvator A, Guo S, Collin M, Lilien L, Baley J. Maternal psychological distress and parenting stress after 
the birth of a very low-birth-weight infant. Journal of the American Medical Association 1999;281(9):799-805. [PUBMED: 10071000]

\section{Slade 2004}

Slade A, Aber JL, Bresgi I, Berger B, Kaplan M. The Parent Development Interview-Revised. Unpublished protocol 2004.

\section{Slade 2005}

Slade A, Grienenberger J, Bernbach E, Levy D, Locker A. Maternal reflective functioning attachment, and the transmission gap: a preliminary study. Attachment \& Human Development 2005;7(3):283-98. [DOI: 10.1080/ 14616730500245880 ]

\section{Sroufe 2005}

Sroufe LA, Egeland B, Carlson E, Collins WA. The Development of the Person: The Minnesota Study of Risk and Adaptation from Birth to Adulthood. New York: The Guilford Press, 2005.

\section{Steele 2010}

Steele H, Siever L. An attachment perspective on borderline personality disorder: advances in gene-environment considerations. Current Psychiatry Reports 2010;12(1):61-7. [DOI: 10.1007/s11920-009-0091-0]

\section{Stein 2006}

Stein A, Woolley H, Senior R, Hertzmann L, Lovel M, Lee $\mathrm{J}$, et al. Treating disturbances in the relationship between mothers with bulimic eating disorders and their infants: a randomized, controlled trial of video feedback. The American Journal of Psychiatry 2006;163(5):899-906.

\section{Sterne 2011}

Sterne JAC, Egger M, Moher D on behalf of the Cochrane Bias Methods Group. Chapter 10: Addressing reporting bias. In: Higgins JPT, Green $S$ (editors). Cochrane Handbook for Systematic Reviews of Interventions Version 5.1.0 [updated March 2011]. The Cochrane Collaboration, 2011. Available from www.cochrane-handbook.org.

\section{Stolk 2008}

Stolk MN, Mesman J, Van Zeijl J, Alink LRA, BakersmanKranenburg MJ, Van Ijzendoorn MH, et al. Early parenting intervention aimed at maternal sensitivity and discipline: a process evaluation. Journal of Community Psychology 2008; 36(6):780-97. [DOI: 10.1002/jcop.20280]

\section{Sumner 1994}

Sumner G, Spietz A (editors). NCAST Caregiver/ParentChild Interaction Teaching Manual. Seattle, WA: NCAST Publictions, University of Washington School of Nursing, 1994.

\section{UNICEF 2008}

UNICEF. The child care transition. A league table of early childhood education and care in economically advanced countries. Innocenti Report Card 8. www.unicef-irc.org/ publications/pdf/rc8_eng.pdf (accessed 25 July 2016).

\section{Van den Boom 1991}

Van den Boom DC. The influence of infant irritability on the development of the mother-infant relationship in the first six months of life. In: Nugent JK, Lester BM, Brazelton TB editor(s). The Cultural Context of Infancy. Vol. 2, Norwood NJ: Ablex, 1991:63-89.

\section{Van Ijzendoorn 1995}

Van IJzendoorn MJ, Juffer F, Duyvesteyn MGC. Breaking the intergenerational cycle of insecure attachment: a review of the effects of attachment-based interventions on maternal sensitivity and infant security. Journal of Child Psychology and Psychiatry 1995;36(2):225-48. [DOI: 10.1111/ j.1469-7610.1995.tb01822.x]

\section{Velderman 2006}

Velderman MK, Bakermans-Kranenburg MJ, Juffer F, Van IJzendoorn MH. Effects of attachment-based interventions on maternal sensitivity and infant attachment: differential susceptibility of highly reactive infants. Journal of Family Psychology 2006;20(2):266-74. [DOI: 10.1037/ 0893-3200.20.2.266]

\section{Vik 2006}

Vik K, Hafting M. Video interaction guidance offered to mothers with postnatal depression: experiences from a pilot study. Nordic Journal of Psychiatry 2006;60(3):234-8. [DOI: 10.1080/08039480600636593]

\section{Waters 1987}

Waters E. Attachment Q-set (Version 3). www.johnbowlby.com (accessed 20 August 2015).

\section{Webster-Stratton 2013}

Webster-Stratton C. The Incredible Years® Programme. www.incredibleyears.com (accessed 3 December 2015).

\section{Weinfield 2004}

Weinfield NS, Whaley GJL, Egeland B. Continuity, discontinuity and coherence in attachment from infancy to late adolescence: sequelae of organization and disorganization. Attachment \& Human Development 2004;6 (1):73-97. [DOI: 10.1080/14616730310001659566]

\section{Yagmur 2014}

Yagmur S, Mesman J, Malda M, Bakermans-Kranenburg MJ, Ekmekci H. Video-feedback intervention increases sensitive parenting in ethnic minority mothers: a randomized control trial. Attachment \& Human Development 2014;16(4):371-86.

\section{Zeanah 1993}

Zeanah CH, Mammen O, Lieberman A. Disorders of attachment. In: Aeanah $\mathrm{CH}$ editor(s). Handbook of Infant Mental Health. New York: Guildford Press, 1993:332-49. 
A P PENDICES

\section{Appendix I. Ovid MEDLINE search strategy}

1 exp Video Recording/

2 VIG.tw.

3 video\$.tw.

4 VIPP\$.tw.

5 VHT.tw.

6 interaction guidance.tw.

7 or/1-6

8 exp Parent-Child Relations/

9 Parenting/

10 Paternal Behavior/

11 maternal behavior/

12 Object Attachment/

13 Reactive Attachment Disorder/

14 (insecure adj3 attachment\$).tw.

15 (secure adj3 attachment\$).tw.

16 (attachment adj3 disorder\$).tw.

17 (parent $\$$ adj3 sensitiv\$).tw.

18 ((mother\$ or maternal\$) adj3 sensitiv\$).tw.

19 ((father\$ or paternal\$) adj3 sensitiv\$).tw.

20 (parent $\$$ adj 3 competenc $\$$ ).tw.

21 ((mother\$ or maternal\$) adj3 competenc\$).tw.

22 ((father\$ or paternal\$) adj3 competenc\$).tw.

23 (parent $\$$ adj3 responsiv\$).tw.

24 (parent $\$$ adj3 positive).tw.

25 ((mother\$ or maternal\$) adj3 responsiv\$).tw.

26 ((father\$ or paternal\$) adj3 responsiv\$).tw.

27 (disorgani\# ed adj3 attachment\$).tw.

28 (parent\$ adj3 (inter-action\$ or interaction\$)).tw.

29 ((mother\$ or maternal\$) adj3 (interaction or inter-action\$)).tw.

30 ((father\$ or paternal\$) adj3 (interaction or inter-action\$)).tw.

31 ( (parent $\$$ or mother $\$$ or maternal $\$$ or father $\$$ or paternal $\$$ or infant $\$$ or child $\$$ ) adj3 (attachment $\$$ or bond $\$$ or relationship $\$$ or dyad\$ or triad\$)).tw.

32 (parent\$ adj3 (intervention $\$$ or skill\$ or train $\$$ or educat $\$$ or program $\$$ )).tw.

33 Caregivers/

34 (carer\$ or caregiver\$ or care giver\$).tw.

35 or/8-34

36 randomized controlled trial.pt.

37 controlled clinical trial.pt.

38 randomi\#ed.ab.

39 placebo $\$ . a b$.

40 drug therapy.fs.

41 randomly.ab.

42 trial.ab.

43 groups.ab.

44 or/36-43

45 exp animals/ not humans.sh.

4644 not 45

477 and 35 and 46

Video feedback for improving parental sensitivity and attachment (Protocol)

Copyright $\odot 2016$ The Cochrane Collaboration. Published by John Wiley \& Sons, Ltd. 
Appendix 2. 'Risk of bias' assessment

\begin{tabular}{|c|c|c|c|}
\hline \multirow[t]{2}{*}{ Domain } & \multicolumn{3}{|l|}{ Criteria for judgement } \\
\hline & Low risk of bias & High risk of bias & Unclear risk of bias \\
\hline Sequence generation & $\begin{array}{l}\text { Unpredictable: random num- } \\
\text { ber table, stratified or block ran- } \\
\text { domisation, computer random } \\
\text { number generator }\end{array}$ & $\begin{array}{l}\text { Predictable: non-random (e.g. } \\
\text { choice of practitioner, availabil- } \\
\text { ity), quasi-random (e.g. ID, day } \\
\text { of visit, date of birth) }\end{array}$ & $\begin{array}{l}\text { Lack of information or partial } \\
\text { information on sequence gener- } \\
\text { ation to make a judgement of } \\
\text { low or high risk of bias }\end{array}$ \\
\hline Allocation concealment & $\begin{array}{l}\text { Unpredictable: sequen- } \\
\text { tially numbered sealed opaque } \\
\text { envelopes, central allocation (e. } \\
\text { g. phone, internet) }\end{array}$ & $\begin{array}{l}\text { Predictable: random sequence } \\
\text { known to personnel in advance, } \\
\text { envelopes without safeguards }\end{array}$ & $\begin{array}{l}\text { Lack of information or partial } \\
\text { information on allocation con- } \\
\text { cealment to make a judgement } \\
\text { of low or high risk of bias }\end{array}$ \\
\hline $\begin{array}{l}\text { Blinding of participants or } \\
\text { personnel }\end{array}$ & $\begin{array}{l}\text { Blinding and unlikely that the } \\
\text { blinding would have been bro- } \\
\text { ken, no blinding or incomplete } \\
\text { blinding but outcome unlikely } \\
\text { to be influenced }\end{array}$ & $\begin{array}{l}\text { No blinding, incomplete blind- } \\
\text { ing and outcome likely to be in- } \\
\text { fluenced }\end{array}$ & $\begin{array}{l}\text { Insufficient evidence of partic- } \\
\text { ipant or personnel blinding to } \\
\text { make a judgement of low or } \\
\text { high risk of bias }\end{array}$ \\
\hline Blinding of outcome assessors & $\begin{array}{l}\text { Blinding and unlikely that the } \\
\text { blinding would have been bro- } \\
\text { ken, no blinding or incomplete } \\
\text { blinding but measurement un- } \\
\text { likely to be influenced }\end{array}$ & $\begin{array}{l}\text { No blinding, incomplete blind- } \\
\text { ing and measurement likely to } \\
\text { be influenced }\end{array}$ & $\begin{array}{l}\text { Insufficient evidence of blind- } \\
\text { ing of outcome assessors to } \\
\text { make a judgement of low or } \\
\text { high risk of bias }\end{array}$ \\
\hline Incomplete outcome data & $\begin{array}{l}\text { No missing data, reasons for } \\
\text { missing data not related to the } \\
\text { outcome, missing data } \\
\text { balanced across groups and rea- } \\
\text { sons similar, proportion miss- } \\
\text { ing or plausible effect size not } \\
\text { enough to have a clinically-rel- } \\
\text { evant effect }\end{array}$ & $\begin{array}{l}\text { Reasons related to outcome and } \\
\text { imbalance in numbers or rea- } \\
\text { sons, inappropriate use of im- } \\
\text { putation, 'as treated' analysis } \\
\text { with substantial departure from } \\
\text { allocation, proportion missing } \\
\text { or plausible effect size enough } \\
\text { to have a clinically-relevant ef- } \\
\text { fect }\end{array}$ & $\begin{array}{l}\text { Lack of information on reasons } \\
\text { for missing data, insufficient ev- } \\
\text { idence of effect of missing data } \\
\text { on outcome, lack of informa- } \\
\text { tion on imputation methods or } \\
\text { insufficient detail on intention- } \\
\text { to-treat and participant depar- } \\
\text { ture from allocation to make a } \\
\text { judgement of low or high risk } \\
\text { of bias }\end{array}$ \\
\hline Selective outcome reporting & $\begin{array}{l}\text { Protocol is available and all } \\
\text { prespecified outcomes of inter- } \\
\text { est to the review reported in } \\
\text { the prespecified way, protocol } \\
\text { is unavailable but all prespeci- } \\
\text { fied outcomes of interest are re- } \\
\text { ported }\end{array}$ & $\begin{array}{l}\text { Outcomes not reported as pre- } \\
\text { specified or expected (e.g. miss- } \\
\text { ing, added, unexpected mea- } \\
\text { surements), outcomes reported } \\
\text { incompletely }\end{array}$ & $\begin{array}{l}\text { Insufficient evidence of selec- } \\
\text { tive outcome reporting to make } \\
\text { a judgement of low or high risk } \\
\text { of bias }\end{array}$ \\
\hline
\end{tabular}

Footnotes

Information in table taken from Cates 2016 [pers comm].

Abbreviations: ID: identifier.

Video feedback for improving parental sensitivity and attachment (Protocol)

Copyright @ 2016 The Cochrane Collaboration. Published by John Wiley \& Sons, Ltd. 


\section{CONTRIBUTIONSOFAUTHORS}

All four review authors contributed to the development of this protocol and approved the final draft. LOH is the guarantor for the review.

\section{DECLARATIONSOF INTEREST}

Leeanne O'Hara received a Cochrane Fellowship Award from the Health and Social Care Research and Development Division, Public Health Agency, Belfast. This was to cover salary expenses, travel, training and research expenses.

Jane Barlow is the lead author of a randomised controlled trial (RCT) of the effectiveness of video interaction guidance in preterm babies, which could potentially be eligible for inclusion in the review; she will not extract data from this study should data become available. The RCT was funded by the Grace Fund. She is also a co-applicant on a recently funded National Institute for Health Research (NIHR), Health Technology Assessment (HTA), feasibility study of the use of Video Feedback Intervention to Promote Positive Parenting (VIPP) with young children with reactive attachment disorder living in foster care. JB began a training programme to learn how to deliver video interaction guidance but discontinued this and therefore did not receive any accreditation. JB is an Editor for the CDPLPG.

Nuala Livingstone is an Editor for the CDPLPG and the Cochrane Editorial Unit.

Geraldine Macdonald is the Co-ordinating Editor of the CDPLPG. GM co-authored a book on behavioural social work in 1980 called Behavioural Social Work and received royalties.

\section{SOURCES OF SUPPORT}

\section{Internal sources}

- Queen's University Belfast, UK.

Salary costs for $\mathrm{LOH}$

\section{External sources}

- Health and Social Care, Research and Development Division, Public Health Agency, UK.

Cochrane Fellowship Award to LOH 